BBA 55267

\title{
THE EFFECT OF DIETARY FAT ON THE MOLECULAR SPECIES OF LECITHIN FROM RAT LIVER
}

\author{
L. M. G. VAN GOLDE AND L. L. M. VAN DEENEN \\ Department of Biochemistry, Laboratory of Organic Chemistry, \\ State University, Utrecht (The Netherlands) \\ (Received April 14th, I966)
}

SUMMARY

I. Lecithins from the liver of rats maintained on diets devoid of essential fatty acids or supplemented with coconut oil or corn oil reveded significant differences in fatty acid composition, whilst monomolecular films of these lecithin samples exhibited only limited differences in force-area characteristics.

2. The individual molecular species in the three lecithin samples were determined by means of the following techniques: (a) fractionation of the lecithin on silica impregnated with silver nitrate, followed by determination of the positional distribution of the fatty acids with snake-venom phospholipase A (EC 3.I.I.4); (b) hydrolysis of the lecithin with phospholipase C (EC 3.I.4.3) from Bacillus cereus and fractionation of the resultant diglycerides on silica impregnated with silver nitrate. Subsequently, the positions of the fatty acid constituents in the diglyceride fractions were determined by hydrolysis with pancreatic lipase (EC 3.I.I.3). The second approach gave the most detailed information and made it possible to recognize between 44 and 23 species. Quantitative determination of the major species accounted for 78.5 to $90.5 \%$ of the molecular composition.

3. Differences in diet induced significant variations in the proportions of the various lecithin species and also brought about qualitative differences. These shifts in the molecular composition of the lecithin samples may contribute to preserving the liquid-crystalline nature of these lipids in membrane structures.

\section{INTRODUCTION}

Although the fatty acid composition of phospholipids in animal membranes can be altered most significantly by dietary means, the physical properties of the lipids isolated remain fairly constant, indicating that nature tries to maintain the structural properties of cell membranes, at least to a certain extent ${ }^{1,2}$. In the light of these observations it became important to consider the phospholipids concerned in terms of individual molccular species. Fatty acids and glycerides have been subfractionated to a considerable extent by chromatography on silica impregnated with silver nitrate 
(refs. 3-6). Recently several laboratories have also utilised this technique for the analysis of phospholipids ${ }^{7-12}$. In the present studics an attempt was made to determine the molecular composition of lecithin from the livers of rats fed on different diets by the following procedures: (a) subfractionation of the lecithins by thin-layer chromatography on silica impregnated with silver nitrate followed by determination of the fatty acid pattern in positions $I$ and 2 of each of the separated lecithins with snake-venom phospholipase A (EC 3.r.I.4); (b) degradation of the phospholipids with phospholipase C from Bacillus cereus (EC 3.I.4.3) and subsequent subfractionation of the diglycerides. The positional distribution of fatty acids in the diglyceride fractions was ascertained by means of hydrolysis with pancrcatic lipase (EC 3.I.I.3)*.

\section{EXPERIMENTAL}

\section{Dietary experiments}

Three groups of six male white rats were fed on different diets:

(A) One group received, for a period of two months commencing 3 weeks after birth, an essential fatty acid-deficient diet consisting of $72 \%$ calories as carbohydrates, $23 \%$ calorics as proteins, $5 \%$ calories as hydrogenated coconut oil, and adcquate amounts of salts and vitamins.

(B) A second group, 6 weeks old, was fed for 2 months on a diet containing $50 \%$ calories as carbohydrates, $\mathrm{x} 6.8 \%$ calories as proteins and $33.3 \%$ calories as coconut oil supplemented with the required amounts of salts and vitamins**.

(C) A third group, also 6 weeks old, was given the same diet as Group B for two months except that in this group the coconut oil was replaced by the same caloric amount of corn oil.

\section{Isolation of lecithin}

After 2 months the animals were sacrificed by bleeding. The livers were removed quickly, rinsed thoroughly with distilled water and extracted immediately according to the method of BLIGH AND DYER ${ }^{13}$. The total liver lipids obtained in this manner were fractionated by means of silicic acid column chromatography using the procedure of HANAHAN ${ }^{14}$ or with thin-layer chromatography on silica using chloroformmethanol-conc. ammonia-water $(70: 30: 2: 3, \mathrm{v} / \mathrm{v})$ as a developer. In this way samples of chromatographically pure lecithins were obtained, as demonstrated by a comparison with synthetic lecithins. In accordance with previous investigations ${ }^{15}$ the amounts of plasmalogens and glyceryl ether phospholipids were negligible.

\section{Subfractionation of lecithin}

The purified lecithins were subfractionated by thin-layer chromatography on silicic acid impregnated with silver nitrate. The plates $(20 \mathrm{~cm} \times 20 \mathrm{~cm})$ were covered with a suspension of $20 \mathrm{~g}$ of silica gel G-Stahl (Merck, Darmstadt), $8.5 \mathrm{~g}$ of Hyflo and $3 \mathrm{~g}$ of calcium sulphate in $78 \mathrm{ml}$ of a $12.5 \%$ solution of silver nitrate. The plates were

* For a preliminary report see ref. to.

** The results obtained with Diet B resembled most closely those observed on lecithin from animals fed on a laboratory chow. Since variations may occur in the fatty acid composition of lecithin from animals fed on different chows these results were not included. 
activated by heating at $1 \mathrm{IO}^{\circ}$ for $\mathrm{I} .5 \mathrm{~h}$ immediately before use. About $20-30 \mathrm{mg}$ of the lecithin samples were applied to the plates and chloroform-abs. ethanol-water $(65: 35: 4, v / v)$ was used as developer. Spots were visualized under ultraviolet light after spraying with a $0.01 \%$ solution of Rhodamine $6 \mathrm{G}$ in water. The subfractions were scraped off the glass plate and repeatedly extracted according to the method of BLIGH AND DYER; the final volume of each extract was $45 \mathrm{ml}$. All manipulations were carried out in a glove-box under a $\mathrm{N}_{2}$ or $\mathrm{CO}_{2}$ atmosphere.

\section{Hydrolysis by phospholipase A}

About ro $\mathrm{mg}$ of lecithin were dissolved in $2 \mathrm{ml}$ of ether; this solution was shaken with $0.5 \mathrm{ml}$ of $0 . \mathrm{I} \mathrm{M}$ borate buffer $(\mathrm{pH} 7.0$ ) containing calcium acetate (final concentration $0.0025 \mathrm{M}$ ) and $2 \mathrm{mg}$ of Crotalus adamanteus venom. After an incubation period of $20-30$ min the degradation was complete, this being checked by thin-layer chromatography on micro-slides coated with silica. The lysolecithins formed and fatty acids liberated were separated by thin-layer chromatography on silica plates $(20 \mathrm{~cm} \times$ Io $\mathrm{cm})$, using chloroform-methanol-water $(65: 35: 4, \mathrm{v} / \mathrm{v})$ as developer.

\section{Hydrolysis by phospholipase C}

About $80 \mathrm{mg}$ of lecithin dissolved in $3 \mathrm{ml}$ of ether were incubated with a solution of a crude enzyme preparation (containing $0.5 \mathrm{mg}$ of protein) from $B$. cereus. After $I \mathrm{~h}$ the hydrolysis was complete and the diglycerides were extracted ${ }^{13}$. There were no I,3-diglycerides present after the incubation, as confirmed with thin-layer chromatography using synthetic $\mathbf{I , 2}$ - and $\mathrm{I}, 3$-diglycerides as reference substances. The I,2-diglyccrides were then subfractionated by thin-layer chromatography on silicic acid impregnated with silver nitrate. The plates were prepared as described by BARRet, DALlas AND BADLEY ${ }^{4}$, using chloroform-abs. ethanol $(93: 7, v / v)$ as developer. After visualisation of the lipids under ultraviolet light with a solution of $0.01 \%$ Rhodamine $6 \mathrm{G}$ in water, the fractions were removed from the plate and extracted immediately using the procedure of BLIGH AND DYER ${ }^{13}$. Again all manipulations were done in an atmosphere of $\mathrm{N}_{2}$ or $\mathrm{CO}_{2}$. The ratio of the subfractions was determined by adding to each subfraction, as an internal standard, a fatty acid not occurring in the lecithin preparation under investigation.

\section{Hydrolysis with pancreatic lipase}

To 5-Io ing of 1,2 -diglycerides were added successively $9 \mathrm{mg}$ of pancreatic lipase (Calbiochem), I ml of I M Tris buffer ( $\mathrm{pH} 8$ ), o.I ml of a $22 \%$ solution of $\mathrm{CaCl}_{2}$ and $0.25 \mathrm{ml}$ of a $0.1 \%$ solution of sodium deoxycholate. This mixture was first warmed for $I \mathrm{~min}$ in a water bath at $40^{\circ}$ and then shaken vigorously for $5 \mathrm{~min}$ at $40^{\circ}$ in order to digest all the $\mathrm{I}_{2} 2$-diglycerides into 2-monoglycerides and free fatty acids. At the end of the incubation period $0.5 \mathrm{ml}$ of $6 \mathrm{M} \mathrm{HCl}$ was added to stop the reaction and the monoglycerides and fatty acids were separated on thin-layer plates $(20 \mathrm{~cm} \times$ Io $\mathrm{cm}$ ) coated with a $0.5 \mathrm{~mm}$ thick layer of silica using light petroleum-ether-formic acid $(60: 40: 1.6, v / v)$ as developer.

\section{Gas-liquid chromatography}

The fatty acids were converted into the corresponding methyl esters by transesterification for a period of $2 \mathrm{~h}$ at $70^{\circ}$ with methanolic $\mathrm{HCl}$ containing $26 \mathrm{~g}$ of $\mathrm{HCl}$ 
per 1. The methyl esters were qualitatively and quantitatively analysed using an $\mathrm{F} \&$ M instrument equipped with a flame ionisation detector and a $2-\mathrm{m}$ column of $10 \%$ polyethylene glycol adipate. The working temperature of the column was $197^{\circ}$. The following fatty acids were used as standards: palmitic acid (Fluka A.G., Switzerland), stearic acid (Fluka A.G.), oleic acid (the Hormel Institute), linoleic acid (Light \& Co., England), and arachidonic acid (the Hormel Institute). All-cis-methyl-5,8,II-eicosatrienoate and all-cis-methyl-7,10,13-eicosatrienoate prepared by chemical synthesis were kindly donated by Dr. D. A. VAN DORP and Dr. H. J. J. PABON (Unilever Research Laboratorium, Vlaardingen). Determination of the position of double bonds by these investigators revealed the absence of positional isomers.

\section{RESULTS}

The effect of diet on the fatty acid composition of lecithin from rat liver is demonstrated in Table I. The animals maintained on a diet depleted of essential fatty acids revealed a very low content of octadienoic acid and eicosatetraenoic acid. The values are in close agreement with the content of linoleic acid and arachidonic acid found by other investigators in liver lecithin from essential fatty acid-deficient rats ${ }^{17-18}$. The percentages of eicosatrienoic acid(s) and octadecaenoic acid are considerably increased in the lecithin of these animals, as compared with the values found for the lecithin of the rats receiving a regimen containing coconut oil or corn oil. An increase in the quantity of administered linoleic acid is clearly reflected by an increased level

\section{TABIE I}

FATTY ACID COMPOSITION OF LIVER LECITHIN OBTAINED FROM RATS FED ON DIFFERENT DIETS

The fatty acid composition in all tables is given in moles \%. Diet $A$, essential fatty acid-deficient diet; Diet $B$, coconut-oil diet; Diet $\mathrm{C}$, corn-oil diet.

\begin{tabular}{|c|c|c|c|c|c|c|c|c|c|}
\hline \multirow{2}{*}{$\begin{array}{l}\text { Fatty } \\
\text { acids }\end{array}$} & \multicolumn{3}{|l|}{ Diet $A$} & \multicolumn{3}{|l|}{$D \operatorname{Dit} B$} & \multicolumn{3}{|l|}{ Diet C } \\
\hline & $\begin{array}{l}\text { Overall } \\
\text { composition }\end{array}$ & I-position & 2 -position & $\begin{array}{l}\text { Overall } \\
\text { composition }\end{array}$ & I-position & a-position & $\begin{array}{l}\text { Overall } \\
\text { composition }\end{array}$ & $I-p o s i t i o n$ & 2 -position \\
\hline $12: 0$ & - & - & - & + & $0 . \mathbf{I}$ & + & + & + & - \\
\hline $14: 0$ & 0.3 & + & - & I. 7 & 2.4 & 0.5 & + & 0.2 & + \\
\hline $15: 0$ & + & + & - & + & 0.2 & + & + & 0.3 & + \\
\hline $16: 0$ & 18.2 & $3^{x} \cdot 3$ & 3.9 & 20.2 & $3^{8.3}$ & 2.3 & 18.9 & 35.9 & 2.2 \\
\hline $16: 1$ & 2.9 & 1.5 & 3.2 & 0.7 & 1.6 & 1.7 & + & I.9 & 0.2 \\
\hline $7: 0$ & - & - & - & + & + & + & + & I. 7 & - \\
\hline $18: 0$ & 25.7 & $47 \cdot 5$ & 1.9 & 27.1 & 51.8 & I. 5 & 24.4 & 42.1 & 1.2 \\
\hline I8: I & 21.8 & 19.2 & 25.2 & I 1.8 & 3.9 & 17.0 & 9.9 & I 5.8 & 5.6 \\
\hline $\mathrm{x} 8: 2$ & I. 7 & - & 3.4 & I 5.0 & I. 8 & 28.3 & I 8.6 & 6.2 & 32.9 \\
\hline $20: 2$ & + & - & + & 0.6 & - & 1.8 & - & - & - \\
\hline $20: 3$ & 23.1 & 0.6 & 48.1 & 3.5 & - & 5.9 & - & - & - \\
\hline $20: 4$ & 6.3 & - & I $4 \cdot 3$ & 19.5 & - & $4 I .1$ & 28.2 & 0.1 & $57 \cdot 7$ \\
\hline
\end{tabular}

of this acid and particularly of arachidonic acid in the liver lecithin. Hydrolysis experiments with phospholipase A from snake venom confirm that the saturated fatty acid constituents are predominantly located at the I-position, whereas the polyunsaturated fatty acids are esterified nearly exclusively at the 2-position. A comparison of the fatty acid distribution between lecithins $\Lambda$ (essential fatty acid-deficient) and $C$ (corn-oil diet) demonstrates the positional interchangeability of different 
polyunsaturated fatty acids found in phospholipids of several origins ${ }^{20,21}$. The most abundant monounsaturated fatty $\operatorname{acid}(\mathrm{s})(\mathrm{I} 8: \mathrm{I})$ is located preferentially at the 2-posi tion of lecithin B; in lecithin A octadecaenoic acid(s) is more randomly distributed among the two ester positions, whereas in lecithin $C$ there is a preference of $I 8: I$ for the $I$-position. As will be demonstrated in this paper these differences in the location of $18: 1$ are due to differences in the proportions of various molecular species among the lecithin preparations.

\section{Molecular species of lecithin $A$}

Subfractionation of lecithin. Chromatography of liver lecithin from rats deficient in essential fatty acids on silica plates impregnated with silver nitrate resulted in three spots. The spot with the lowest mobility $\left(S_{I}\right)$, representing only a small fraction of the total lecithin, contained a considerable amount of $20: 4$ and $20: 3$ (Table II).

TABLE II

FATTY ACID COMPOSITION OF LIVER LECITHINS FROM ESSENTIAL FATTY ACID-DEFICIENT RATS (DIET A) AFTE SUBFRACTIONATION ON SILVER NTTRATE-IMPREGNATED SILICA

\begin{tabular}{|c|c|c|c|c|c|c|c|c|c|}
\hline \multirow{2}{*}{$\begin{array}{l}\text { Fatty } \\
\text { acids }\end{array}$} & \multirow{2}{*}{$\frac{S I}{\text { Overall }}$} & \multirow[b]{2}{*}{ I-position } & \multirow[b]{2}{*}{$2-p o s i t i o n$} & \multicolumn{3}{|l|}{$S_{I I}$} & \multirow{2}{*}{$\begin{array}{l}\frac{S_{I I I}}{\text { Overall }} \\
\text { composition }\end{array}$} & \multirow[b]{2}{*}{$I-p o s i t i o n$} & \multirow[b]{2}{*}{2 -positio } \\
\hline & & & & $\begin{array}{l}\text { Overall } \\
\text { composition }\end{array}$ & $I-$ position & $2-p o s i t i o n$ & & & \\
\hline I4:0 & + & - & - & + & - & - & + & - & - \\
\hline $15: 0$ & - & - & -- & - & - & - & + & - & - \\
\hline $16: 0$ & 20.0 & 40.7 & + & 23.2 & 39.9 & 3.2 & 20.9 & $3^{8.1}$ & 5.6 \\
\hline $16: x$ & +4 & - & $-m$ & 3.2 & - & 1.6 & 8.4 & 12.1 & $4 \cdot 3$ \\
\hline $18: 0$ & 23.6 & $5 \mathrm{I} \cdot 3$ & 1 & 24.2 & 48.4 & 2.0 & $2 \times .6$ & $45 \cdot 5$ & + \\
\hline I 8: I & $4 \cdot 5$ & 7.9 & + & 23.1 & $\mathbb{I} \pm .7$ & 30.9 & 45.4 & 4.7 & 90.1 \\
\hline I $8: 2$ & $+r$ & - & 2.3 & + & $-\ldots$ & 4.0 & $3 \cdot 5$ & - & + \\
\hline $20: 2$ & - & - & + & - & $m$ & - & + & - & $\omega$ \\
\hline $20: 3$ & 30.6 & - & 00.0 & $23 \cdot 7$ & - & 52.9 & - & - & - \\
\hline $20: 4$ & 22.2 & - & $37 \cdot 7$ & 2.5 & $-\cdots$ & $5 \cdot 4$ & - & - & - \\
\hline
\end{tabular}

A second fraction ( $S_{n}$ ) appeared to contain only a small amount of $20: 4$, but $20: 3$ was abundant, whereas the content of $18: \mathrm{I}$ was higher as compared with $\mathrm{S}_{\mathrm{I}}$. Although both fractions were clearly separated in a number of experiments, this fractionation was not achieved. A third fraction ( $S_{I I I}$ ) moving in all experiments much faster than $S_{r}$ and $S_{I I}$ appeared to contain mainly monounsaturated and saturated fatty acids. These results are in contrast to those obtained by KAUFMAN, WESSELS AND BondoPADHYAYA ${ }^{7}$ Who claimed a separation of natural lecithins into nine subfractions. Recently, ARvioson 11 modified KAUFMANN's procedure and obtained $2-6$ subfractions, depending on the origin of the lecithin sample. The results of phospholipase A hydrolysis of the subfractions are in fair agreement with those obtained for the fatty acid distribution in the non-fractionated lecithin sample. The data obtained with Fraction $S_{I}$ indicate the occurrence of the lecithin species: I6:0/20:3, I6:0/20:4, 18:0/20:3 and $18: 0 / 20: 4$. (The first- and second-mentioned fatty acid occupying the I- and 2-ester positions, respectively.) However, the data obtained do not permit any conclusions about the amount of these individual species. The presence of the species $16: 0 / 20: 3$ and $18: 0 / 20: 3$ is also suggested by the analytical data obtained on $S_{I I}$. Therefore, it seems likely that $S_{I}$ is contaminated on the plate with $S_{I I}$ which is quantitatively the more important fraction. Fraction $S_{111}$ was found to have $90 \%$ of 
$\mathrm{I} 8: \mathrm{I}$ at the 2 -fatty acid ester position, allowing the conclusion that $16: 0 / 18: I$ is present. More quantitative information on these species could be obtained by the second approach.

Subfractionation of diglycerides. After complete conversion of the phospholipid sample with phospholipase $C$ from $B$. cereus the I,2-diglycerides were subjected to chromatography on silica plates containing silver nitrate. Lecithin preparation $A$ resulted in seven spots, the separation depending on the number of double bonds, the location of the double bonds in the paraffinic chains and to some extent on the positional distribution of the fatty acids. Subfraction $S_{1}$ contained all of the $20: 4$ present in the diglyceride sample (Table III). This polyunsaturated fatty acid together with a small amount of $20: 3$ was found to occupy exclusively the 2-position,

\section{TABLE III}

FATTY ACID COMPOSITION OF DIGLYCERIDES OBTAINED AFTER PHOSPHOLIPASE C HYDROLYSIS OF LIVER LECITHIN FROM ESSENTIAL FATTY ACID-DEFICIENT RATS (DIET A) AND SUBSEQUENT FRACTIONATION ON SILVER NTTRATF-TMPREGNATED SILTCA

\begin{tabular}{|c|c|c|c|c|c|c|c|}
\hline \multirow[t]{2}{*}{ Fatty acids } & \multicolumn{7}{|c|}{ Fatty acid composition } \\
\hline & $S_{1}$ & $S_{2}$ & $S_{3}$ & $S_{4}$ & $S_{5}$ & $S_{8}$ & $S_{7}$ \\
\hline $\mathrm{I}_{4}: 0$ & + & - & + & - & - & 0.9 & 3.7 \\
\hline I 5:0 & - & - & - & - & - & - & + \\
\hline $16: 0$ & $15 \cdot 3$ & 17.0 & 14.2 & 20.8 & + & 26.4 & 60.9 \\
\hline $\pm 6: x$ & 2.4 & - & - & 4.6 & I $4 \cdot 5$ & G.1 & $4 \cdot 3$ \\
\hline I8:0 & 26.5 & 37.4 & 35.2 & 32.5 & + & 21.7 & $3 \mathrm{I} . \mathrm{I}$ \\
\hline $18: 1$ & $5 \cdot x$ & 1.0 & 2.3 & II.5 & $85 \cdot 5$ & 45.0 & + \\
\hline $18: 2$ & - & - & 0.9 & 25.0 & - & - & - \\
\hline $20: 2$ & - & - & - & $5 \cdot 5$ & - & - & $\cdots$ \\
\hline $20: 3$ & 2.5 & 44.6 & $47 \cdot 3$ & - & - & $-\ldots$ & - \\
\hline $20: 4$ & $48 . x$ & & - & - & - & - & - \\
\hline \multirow{4}{*}{$\begin{array}{l}\text { Per cent of } \\
\text { lecithin }\end{array}$} & & & & & & & \\
\hline & 26.4 & $13 \cdot 3$ & 22.7 & 7.2 & I I.5 & 20.5 & 8.3 \\
\hline & \multicolumn{7}{|c|}{ Fatty acid composition of the 2-position* } \\
\hline & $S_{1}$ & $S_{2}$ & $S_{8}$ & & $S_{5}$ & $S_{6}$ & $S_{7}$ \\
\hline $14: 0$ & - & - & -- & & - & - & + \\
\hline $15: 0$ & - & - & - & & - & - & + \\
\hline $16: 0$ & + & + & + & & - & 6.5 & 80.0 \\
\hline $16: 1$ & - & - & - & & $4 \cdot 5$ & $3 \cdot 2$ & $7 \cdot 3$ \\
\hline $18: 0$ & + & $t$ & + & & - & - & 12.7 \\
\hline $18: 1$ & - & - & - & & $95 \cdot 5$ & 90.3 & + \\
\hline I $8: 2$ & - & - & - & & - & - & - \\
\hline $20: 2$ & - & -. & - & & - & - & - \\
\hline $20: 3$ & 6.1 & 100.0 & 100.0 & & - & - & - \\
\hline $20: 4$ & 94.0 & & - & & - & - & - \\
\hline
\end{tabular}

* Hydrolysis with pancreatic lipase was used to determine this fatty acid composition. Fraction 4 was present in too small an amount for hydrolysis with pancreatic lipase.

as demonstrated by hydrolysis with pancreatic lipase. This enzyme is known to act preferentially at the I-position of the diglycerides ${ }^{22,23}$ and the results obtained in the present study are in good agreement with those from the phospholipase A hydrolysis of the lecithin preparations and their subfractions. Taking into account the very good separation between $S_{1}$ and $S_{2}$, it seems legitimate to make the assumption that all species present in fraction $S_{1}$ contain four double bonds. Assuming that 20:3 is combined with $I 8: I$ and $I 6: I$ (giving the lecithin species $I 8: I / 20: 3$ and $I 6: I / 20: 3$ ) it is 
concluded that the saturated fatty acids present at the I-position are combined with $20: 4$ located at the 2 -position. The major molecular species present in this diglyceride subfraction are apparently $16: 0 / 20: 4$ and $18: 0 / 20: 4$ lecithins. The relative amounts of these individual species in the sample of lecithin A can be calculated from the observation that Subfraction $S_{1}$ represents $16.4 \%$ of the total glycerides (Table III). For example, the $18: 0 / 20: 4$ species represents $53 / 100 \times 16.4$ or $8.7 \%$ of the total lecithin, 53 representing the percentage of the I-position of Fraction $S_{1}$, occupied by stearic acid. Fractions $S_{2}$ and $S_{3}$ which represent two neighbouring spots (being, however, resolved to a fair degree) exhibited a similar fatty acid composition. In both subfrac-

\section{TABLE IV}

FATTY ACID COMPOSITION OF LIVER LECITHINS FROM COCONUT OIL-FED RATS (DIET B) AFTER SUBFRACTIONATION ON SILVER NITRATE-IMPREGNATED SILICA

\begin{tabular}{|c|c|c|c|c|c|c|}
\hline \multirow[t]{2}{*}{ Fatty acids } & \multicolumn{3}{|l|}{$S_{I}$} & \multicolumn{3}{|l|}{$S_{I I}$} \\
\hline & $\begin{array}{l}\text { Overall } \\
\text { composition }\end{array}$ & $I$-position & $2-p o s i t i o n$ & $\begin{array}{l}\text { Overall } \\
\text { composition }\end{array}$ & $r$-position & 2 -position \\
\hline $12: 0$ & + & - & - & + & + & - \\
\hline$x_{4}: 0$ & I.I & 2. I & - & 3.0 & $3 \cdot 5$ & I.O \\
\hline $15: 0$ & + & + & - & + & + & + \\
\hline $16: 0$ & 19.0 & $34 \cdot 4$ & 1.5 & $25 \cdot 5$ & 46.0 & 5.2 \\
\hline $16: 1$ & 0.6 & + & + & 2.4 & + & 4.2 \\
\hline $17: 0$ & + & + & - & - & - & - \\
\hline $18: 0$ & $3^{0.1}$ & 56.3 & 0.6 & 25.2 & 46.7 & $1 \cdot 3$ \\
\hline $18: 1$ & 3.8 & $4 \cdot 3$ & 2.0 & 19.7 & 3.8 & 36.6 \\
\hline $18: 2$ & 5.6 & 2.5 & IO.X & 24.2 & + & 51.8 \\
\hline $20: 2$ & 0.9 & - & 1.4 & - & - & - \\
\hline $20: 3$ & 4.2 & - & 7.8 & + & m.m & - \\
\hline $20: 4$ & 34.9 & - & 76.5 & + & - & - \\
\hline
\end{tabular}

tions eicosatrienoic acid occupied over $99 \%$ of the 2 -position of the diglycerides. However, the relative retention times measured during gas-chromatographic analysis suggested that $\Delta 7, \mathrm{IO}, 13$-eicosatrienoic acid is present mainly in $\mathrm{S}_{2}$, whereas $\Delta 5,8$, I $\mathrm{I}$-eicosatrienoic acid occurs predominantly in $S_{3} *$. For the calculation of the lecithin species no distinction has been made between the two isomeric fatty acid constituents (Table VIII). Fraction $\mathrm{S}_{4}$ contained the dienoic acids $18: 2$ and $20: 2$; these fatty acids were not present in any other diglyceride fraction. The fatty acid distribution of this minor fraction has not been determined, but the analysis of the lecithin sample A (Table I) and its subfractions (Table II) indicates that these dienoic acids are located exclusively at the 2-position. The analytical data on this fraction available to date do not allow us to formulate any particular species, certainly not on a quantitative basis. Subfraction $S_{5}$ contained nearly exclusively the monounsaturated fatty acid constituents $I 6: I$ and $I 8: I$; the relative quantity of the latter at the 2-position exceeded that of the former. It is only possible to calculate minimal and maximal values for the four possible species viz. I8:I/I8:I, I6:I/I8:I, I6:I/I6:I and I8:I/I6:I. The two first-mentioned species are quantitatively the most important ones and the analytical data make their presence unambiguous, but it cannot be stated with certainty

* This tentative conclusion was supported by experiments with the synthetic isomers provided by Dr. D. A. van Dorp and Dr. H. J. J. PABON (Unilever Research Laboratory, Vlaardingen). These compounds revealed similar differences in retention times, this also being so when present as a mixture. 
that the two minor species are both definitely present. Furthermore, it is worth noting that the species containing two unsaturated fatty acid constituents were separated from the species containing one diunsaturated fatty acid, a result also obtained by RENKONEN ${ }^{12}$ in the analysis of diglyceride acetates derived from brain lecithin. On the other hand, it cannot be precluded that Fraction $S_{4}$ contained some species with two monounsaturated fatty acids. Subfraction $S_{6}$ contained about $49 \%$ saturated and $5 \mathrm{r} \%$ monounsaturated fatty acids; $18: \mathrm{I}$ and $\mathrm{I} 8: 0$ were exclusively located at the 2- and I-positions, respectively. On the other hand, I6:I and I6:0 are located on both ester positions. Since the species containing saturated fatty acids only are recovered in a distinct fraction(s) it is reasonable to base the determination of the species present in $S_{\beta}$ on the fact that each contains one monounsaturated fatty acid. The major species which can be deduced are $16: 0 / 18: \mathrm{I}$ and $18: 0 / 18: \mathrm{I}$; in addition, I6:I/I6:0, 16:0/16:I and 18:0/I6:I can be envisaged as possible members. Depending on the amount of $16: 0 / 16: \mathrm{I}$ (unknown; maximal value about $0.7 \%$ of the total lecithin) the quantity of $16: 0 / 18:$ I may vary between 8.8 and $9.5 \%$ of the lecithin preparations. Similarly the species $18: 0 / 18: 1$ may represent between 8.2 and $8.9 \%$ of the lecithin. The species $16: 1 / 16: 0$ may account maximally for about $1 \%$

TABLE V

FATTY ACID COMPOSITION OF DIGLYCERIDES OBTAINED AFTER PHOSPHOLIPASE C HYDROLYSIS OF LIVER LECITHIN FROM RATS FED ON A COCONUT-OIL DIET AND SUBSEQUENT FRACTIONATION ON SILVER NITRATE-TMPREGNATED SILICA

\begin{tabular}{|c|c|c|c|c|c|}
\hline \multirow[t]{2}{*}{ Fatty acids } & \multicolumn{5}{|c|}{ Fatty acid composition } \\
\hline & $\overline{S_{1}}$ & $S_{1 y}$ & $S_{3}$ & $S_{4}$ & $S_{5}$ \\
\hline $12: 0$ & 0.4 & + & 0.7 & + & + \\
\hline $14: 0$ & $\mathrm{I} .5$ & $3 \cdot 7$ & 1.8 & 2.9 & 9.0 \\
\hline $15: 0$ & 0.5 & 0.7 & 1 & 0.5 & $\mathbf{1} \cdot 5$ \\
\hline $16: 0$ & 16.9 & 14.6 & 15.4 & 32.7 & $53 \cdot 4$ \\
\hline $16: \mathbf{I}$ & I.O & 0.6 & 2.3 & 5.0 & $3 \cdot 3$ \\
\hline $\mathrm{x} 6: 2$ & + & - & + & + & + \\
\hline $18: 0$ & $27 \cdot 4$ & $25 . \mathrm{I}$ & 24.9 & I $4 . I$ & 16.0 \\
\hline $18: 1$ & 2.1 & 2.8 & $4 \cdot 7$ & 44.8 & 16.8 \\
\hline $18: 2$ & 0.2 & 2.6 & 50.1 & + & - \\
\hline $20: 2$ & - & + & - & - & - \\
\hline $20: 3$ & - & 50.0 & - & - & - \\
\hline $20: 4$ & 49.8 & - & - & - & - \\
\hline \multirow[t]{3}{*}{ Per cent of total lecithin } & 27.8 & 16.9 & 26.4 & 21.5 & $7 \cdot 4$ \\
\hline & \multicolumn{4}{|c|}{ Fatty acid composition of the 2 -position* } & \\
\hline & $\overline{S_{1}}$ & $S_{2}$ & $S_{8}$ & $S_{4}$ & \\
\hline $12: 0$ & - & - & - & - & \\
\hline$I_{4}: 0$ & - & - & - & - & \\
\hline $15: 0$ & - & - & - & $-m$ & \\
\hline $16: 0$ & 1.2 & + & I.5 & 6.3 & \\
\hline $16: 1$ & - & - & - & - & \\
\hline $16: 2$ & - & - & - & - & \\
\hline $18: 0$ & 0.9 & + & I.I & 3.0 & \\
\hline r 8:r & + & - & - & 90.6 & \\
\hline I $8: 2$ & - & - & 97.3 & - & \\
\hline $20: 2$ & - & - & - & - & \\
\hline $20: 3$ & - & I00.0 & - & - & \\
\hline $20: 4$ & 97.9 & - & - & $-\cdots$ & \\
\hline
\end{tabular}

* Hydrolysis with pancreatic lipase was used to determine this fatty acid composition. Fraction 5 was present in too small an amount for hydrolysis with pancreatic lipase. 
of the lecithin. A relatively small fraction $\left(S_{7}\right)$ appeared to contain more than $95 \%$ of saturated fatty acid constituents. Inasmuch as palmitic acid was the major constituent esterified to the 2-position, the species $16: 0 / 16: 0$ and $18: 0 / 16: 0$ must certainly be present. Taking into account the possible presence of $16: 0 / 18: 0$ and $18: 0 /$ $18: 0$, the values for $16: 0 / 16: 0$ and $18: 0 / 16: 0$ can be calculated to vary between $2.4-3.5 \%$ and $3.3-4.1 \%$ of the total lecithin, respectively.

\section{Molecular species of lecithin B}

Subfractionation of lecithin obtained from the liver of coconut oil-fed rats on silver nitrate-impregnated silica yielded only two spots. The fatty acid composition of these two subfractions $\mathrm{S}_{I}$ and $\mathrm{S}_{\mathrm{II}}$ is recorded in Table IV together with the positional distribution of the fatty acids. The eicosatrienoic and eicosatetraenoic acids were all recovered in Subfraction $\mathrm{S}_{\mathrm{r}}$ which had the lowest $R_{F}$ value, whereas most of the octadecadienoic and octadecaenoic acids were recovered in Subfraction $S_{I I}$. In view of the high percentages of palmitic acid and stearic acid at the I-position of Subfraction $\mathrm{S}_{\mathrm{I}}$ and the significant amount of eicosatetraenoic acid at the 2 -ester position, it is clear that the species $16: 0 / 20: 4$ and $18: 0 / 20: 4$ are present in this lecithin. If similar reasoning is applied to the results obtained by hydrolysis of Subfraction $\mathrm{S}_{\mathrm{II}}$ with phospholipase $A$, then $I 6: 0 / 18: 2$ and $18: 0 / 18: 2$ must exist. More detailed information was obtained by fractionation of the 1,2 -diglycerides. Five fractions were obtained (Table V) containing predominantly tetraenoic, trienoic, dienoic, monoenoic and saturated fatty acid constituents. The unsaturated fatty acid constituents, which accounted for $45-50 \%$ of the total fatty acids, were mainly located at the 2-position. The analytical data on Subfraction $S_{1}$ allowed us to calculate the quantities of the species I6:0/20:4, I8:0/20:4 and I8:I/20:4 (Table VIII). Furthermore other species, e.g. I4:0/20:0, present in small quantities, are recovered in this fraction. Subfraction $S_{2}$ apparently contains $I 6: 0 / 20: 3$ and $18: 0 / 20: 3$ as major components, while in $S_{3} 16: 0 / 18: 2$ and $18: 0 / 18: 2$ are the predominating species (Table VIII). No distinct subfraction containing two monounsaturated fatty acid constituents was obtained from this lecithin preparation. Subfraction $S_{4}$ revealed the presence of I6:0/I $8: I$ and $\mathrm{I} 8: 0 / \mathrm{I} 8:$ I. If we assume that all species present in this fraction contain one monounsaturated fatty acid, then it is also possible to calculate the quantities of $\mathrm{I} 6: \mathrm{I} / \mathrm{I} 6: 0$ and I6:I/I8:0. Subfraction $S_{5}$ was not degraded with pancreatic lipase, but probably contains a number of species with two saturated fatty acids. It is not clear why this fraction contains a certain quantity of monounsaturated fatty acids. It may be of interest to investigate whether there is a difference between $S_{4}$ and $S_{5}$ with respect to the content of trans fatty acids.

\section{Molecular species of lecithin $C$}

Subfractionation of the intact phospholipid preparation gave quantitative information about the occurrence of only a few molecular species (Table VI). After chromatography of the diglycerides five subfractions were obtained (Table VII). The major fraction, $S_{1}$, consisted of a number of species containing 20:4 at the 2position viz. I6:0/20:4, I8:0/20:4 and, remarkably, also I8: r/20:4. The lecithin $\mathrm{C}$, in contrast to lecithins $\mathrm{B}$ and $\mathrm{A}$, did not furnish a spot containing eicosatrienoic acid, although Subfraction $\mathrm{S}_{2}$ contained a considerable quantity of diunsaturated and monounsaturated fatty acids. The majority of the species in this fraction consisted 
TABLE VI

FATTY ACID COMPOSITION OF LIVER LECITHINS FROM CORN OIL-FED RATS (DIET C) AFTER SUBFRACTIONATION ON SILVER NITRATE-IMPREGNATED SILICA

\begin{tabular}{|c|c|c|c|c|c|c|}
\hline \multirow[t]{2}{*}{ Fatty acids } & \multicolumn{3}{|l|}{$S_{I}$} & \multicolumn{3}{|l|}{$\underline{S_{I I}}$} \\
\hline & $\begin{array}{l}\text { Orerall } \\
\text { composition }\end{array}$ & $T-$ fonsition & a-position & $\begin{array}{l}\text { Onpenall } \\
\text { composition }\end{array}$ & $T$-position & a-position \\
\hline $12: 0$ & - & - & - & - & - & - \\
\hline$I_{4}: 0$ & + & + & - & 0.2 & + & - \\
\hline I $5: 0$ & + & + & - & O.I & + & - \\
\hline $16: 0$ & 17.2 & 32.8 & $\mathbf{I} .6$ & 25.2 & $4^{\mathrm{r} .9}$ & 6.7 \\
\hline $16: 1$ & 0.8 & I. 6 & 0.4 & I, 2 & r. 7 & + \\
\hline $\mathrm{r} 7: 0$ & + & 1.0 & + & 0.5 & - & + \\
\hline $18: 0$ & 26.8 & 48.5 & I. 8 & 20.0 & 37.8 & I. 3 \\
\hline $8: 1$ & 8.9 & I 2.5 & 1.6 & 14.0 & 15.9 & 14.4 \\
\hline $18: 2$ & $7 \cdot 7$ & 3.5 & 9.4 & $3^{8.9}$ & 2.7 & 77.6 \\
\hline $20: 2$ & - & - & - & - & - & - \\
\hline $20: 3$ & - & - & - & - & - & - \\
\hline $20: 4$ & $3^{8.7}$ & + & 85.2 & - &.- & - \\
\hline
\end{tabular}

TABLE VII

FATTY ACID COMPOSITION OF DIGLYCERIDES OBTAINED AFTER PHOSPHOLIPASE C HYDROLYSIS OF LIVER LECITHIN FROM RATS FED ON A CORN-OIL DIET AND SUBSEQUENT SUBFRACTIONATION ON SILVER NITRATE-IMPREGNATED SILICA

\begin{tabular}{|c|c|c|c|c|c|}
\hline \multirow[t]{2}{*}{ Fatty acids } & \multicolumn{5}{|c|}{ Fatty acid composition } \\
\hline & $\overline{S_{1}}$ & $S_{2}$ & $S_{\mathbf{3}}$ & $S_{4}$ & $S_{5}$ \\
\hline I2:0 & - & - & + & - & - \\
\hline$I_{4}: 0$ & + & + & + & + & + \\
\hline $15: 0$ & + & + & + & - & + \\
\hline $16: 0$ & $\mathrm{I} 4.4$ & 9.0 & 23.6 & $33 \cdot 2$ & 64.7 \\
\hline $16: 1$ & + & 1.7 & + & 1.3 & + \\
\hline $16: 2$ & 0.6 & 2.0 & + & + & + \\
\hline $18: 0$ & 29.8 & 8.6 & 22.9 & 1.4 .2 & 20.8 \\
\hline $18: 1$ & 5.0 & 34.8 & 2.8 & 45.6 & 14.5 \\
\hline $18: 2$ & + & 43.9 & $5^{0.7}$ & 5.6 & - \\
\hline $18: 3$ & - & + & - & - & - \\
\hline $20: 2$ & - & - & - & - & - \\
\hline $20: 3$ & - & - & - & - & - \\
\hline $20: 4$ & $5^{0} .2$ & - & - & - & - \\
\hline \multirow[t]{2}{*}{ Per cent of total lecithin } & 38.5 & II.I & $33 \cdot 7$ & I $2 . \mathrm{I}$ & 4.5 \\
\hline & \multicolumn{5}{|c|}{ Fatty acid composition of the 2 -position* } \\
\hline $12: 0$ & - & - & - & - & \\
\hline $14: 0$ & - & + & - & - & \\
\hline 15:0 & - & + & - & - & \\
\hline $16: 0$ & + & 7.2 & 4.8 & 12.2 & \\
\hline $16: I$ & - & 7.0 & + & + & \\
\hline $16: 2$ & - & 2.9 & + & 6.0 & \\
\hline $18: 0$ & + & I. 8 & 5.8 & 4.5 & \\
\hline 18:I & - & I 3.6 & 2.4 & $77 \cdot 3$ & \\
\hline $18: 2$ & - & 67.5 & 87.0 & 17.3 & \\
\hline $18: 3$ & - & - & - & - & \\
\hline $20: 2$ & - & - & - & - & \\
\hline $20: 3$ & - & - & - & - & \\
\hline $20: 4$ & 100.0 & - & - & - & \\
\hline
\end{tabular}

* Hydrolysis with pancreatic lipase was used to determine this fatty acid composition. Fraction 5 was present in too small an amount for hydrolysis with pancreatic lipase. 
TABLE VIII

MAJOR MOLECULAR SPECIES OF LIVER LECITHIN FROM RATS FED ON DIFFERENT DIETS: ESSENTIAL FATTY ACID-DEFICIENT DIET (A), COCONUT-OIL DIET (B) AND CORN-OLL DIET (C)

\begin{tabular}{lllll}
\hline I-position & 2-position & $A^{*}$ & $B$ & $C$ \\
\hline I6:0 & I6:0 & 3.5 & $* *$ & $* *$ \\
$18: 0$ & $16: 0$ & 4 & $* *$ & $* *$ \\
$16: 0$ & $18: I$ & 9.5 & 12.5 & 6.5 \\
$18: 0$ & $18: 1$ & 9 & 5 & 3 \\
$16: 0$ & $18: 2$ & + & 7.5 & 14 \\
$18: 0$ & $18: 2$ & + & 13 & 13.5 \\
$16: 0$ & $20: 3$ & 11 & 5 & - \\
$18: 0$ & $20: 3$ & 26 & 8.5 & - \\
$16: 0$ & $20: 4$ & 5 & 9 & 11 \\
$18: 0$ & $20: 4$ & 8.5 & 15 & 23 \\
$16: 1$ & $18: 1$ & 3 & -- & - \\
$18: 1$ & $18: 1$ & 8.5 & - & - \\
$18: 1$ & $18: 2$ & - & 2 & 4 \\
$18: 1$ & $20: 3$ & 2.5 & - & - \\
$18: 1$ & $20: 4$ & - & 1 & 4 \\
\hline
\end{tabular}

* In some cases only the maximal value is given (see text).

** Not determined.

of $I 8: I / I 8: 2$ and perhaps $I 8: 2 / I 8: I$, while this spot is believed to be contaminated to some extent with $\mathrm{S}_{3}$, containing as major species $\mathrm{I} 6: 0 / \mathrm{I} 8: 2$ and $\mathrm{I} 8: 0 / \mathrm{I} 8: 2$ (Table VIII). It seems likely that small amounts of $18: 2 / 16: 0$ and $I 8: 2 / 18: 0$ are also present in this subfraction. Subfraction $\mathrm{S}_{4}$ contains $\mathrm{I} 6: 0 / \mathrm{I} 8: \mathrm{I}$ and $\mathrm{I} 8: 0 / \mathrm{I} 8: \mathrm{I}$ as major components and probably also small quantities of species with a reversed distribution of fatty acids. As in the other lecithin preparation, Subfraction $S_{5}$ yielded a large quantity of saturated fatty acids as well as octadecaenoic acid.

\section{DISCUSSION}

Comparing the two procedures utilized for the determination of the molecular species of lecithin, analysis of the diglycerides was found to give much more information than direct subfractionation of the lecithin sample. The latter method was improved recently by ARviDson, but the results obtained in both studies on rat-liver lecithin demonstrated that, to date, the former procedure is still superior. Our results on the subfractionation of diglycerides formed cnzymically from phospholipids are in good agreement with those of RENKONEN ${ }^{\mathbf{9}, 12}$ who converted the phospholipids into diglyceride acetates. Rapid enzymic hydrolysis with phospholipase $C$ may have certain advantages, and the present results indicate that the hydrolysis products can be utilized directly for subfractionation. Although it is possible to recognize the major molecular species by this technique, a complete quantitative analysis has not yet been achieved. Further improvement of the technique is necessary before a fully complete lecithin composition can be given with certainty.

It was the purpose of the present study to account for the limited differences in the force-area characteristics measured in monolayer studies of the three lecithin preparations. Previous studies on synthetic phospholipid species containing defined fatty acid constituents demonstrated that the interfacial behaviour is governed mainly by the nature of the paraffinic side-chains, a decrease of chain-length or an increase of 
unsaturation causing an expansion of the film ${ }^{25}$. As demonstrated in Fig. I the three liver lecithin preparations revealed liquid-expanded films with the average molecular area of the samples increasing in the order A, B and C. This is not surprising since in the same sequence there is an increase in unsaturation of these lecithin samples. A calculation of the total number of double bonds (by multiplying the percentages of monoenoic, dienoic, trienoic and tetraenoic fatty acids by $\mathrm{I}, 2,3$ and 4 , respectively) gives the following values: A I23, B I32 and C I60. From a comparison of the proportions of the major species in lecithins $B$ and $C$ it may be seen that the presence of corn oil in the diet causes a considerable increase of $16: 0 / 18: 2$ and $18: 0 / 20: 4$. No increase was observed for $18: 0 / 18: 2$ and further investigations are required to confirm this result. On the other hand, the increase of these species is accompanied by a decrease of $16: 0 / 18: I$, $I 8: 0 / 18: I$ and the disappearance of $16: 0 / 20: 3$ and $I 8: 0 / 20: 3$. These shifts may to

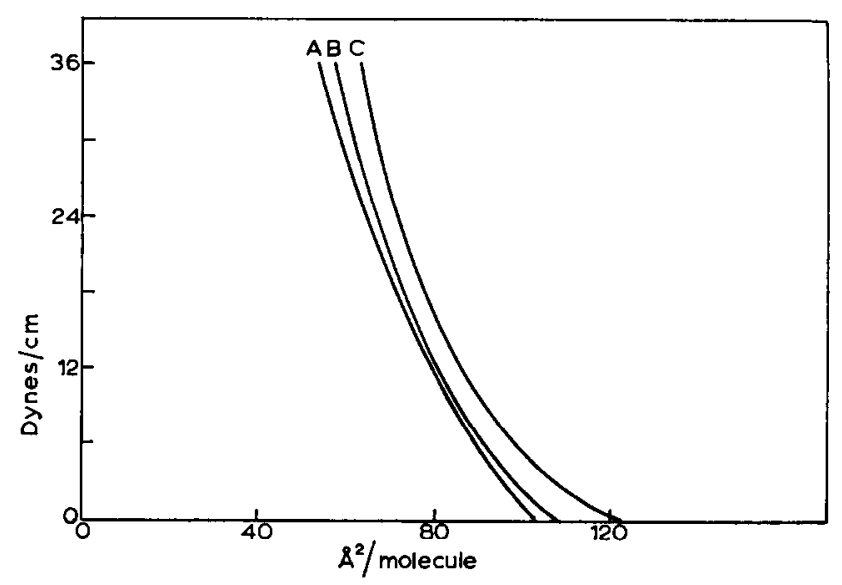

Fig. I. Force-area characteristics of liver lecithin from rats fed on different diets: essential fatty acid-deficient diet (A), coconut-oil diet (B) and corn-oil diet (C). The experiments were carried out with a Langmuir-Adam trough at the air-water interphase at $22^{\circ}$. For each sample at least three experiments were carried out, the range being about $0.5 \AA^{2}$ per molecule.

some extent counteract the physical effects brought about by the increased quantities of $16: 0 / 18: 2$ and $18: 0 / 20: 4$. Furthermore, it is intriguing that the increase of $20: 4$ (located nearly exclusively at the 2-position) is accounted for by an increase of the species containing stearic acid at the I-position rather than by an increase of the species containing palmitic acid. The results on lecithin A confirm and extend previous observations on the replacement of fatty acids of the linoleic acid family by those of the oleic acid family ${ }^{16-19,24,28-28}$ and the positional interchangeability of these polyunsaturated fatty acids in essential fatty acid deficiency 20,21 . The relative quantitics of $16: 0 / 18: 2, I 8: 0 / 18: 2,16: 0 / 20: 4,18: 0 / 20: 4$ and $18: 1 / 20: 4$ are decreased and those of $\mathrm{I} 6: 0 / \mathrm{I} 8: \mathrm{I}, \mathrm{I} 8: 0 / \mathrm{I} 8: \mathrm{I}, \mathrm{I} 6: 0 / 20: 3, \mathrm{I} 8: 0 / 20: 3$ and $\mathrm{I} 8: \mathrm{I} / 20: 3$ are increased as compared with lecithin $\mathrm{C}$ (and to a lesser extent with lecithin B). It is worth noting that $20: 3$ appears to exhibit the same preference as $20: 4$ for occurring with stearic acid. This result is in agreement with the recent studies of Collins ${ }^{24}$, who analysed lecithins in the livers of rats deficient in essential fatty acids by means of countercurrent distribution. Furthermore, it can be noted that in lecithin A considerable 
quantities of $\mathrm{I} 8: \mathrm{I} / \mathrm{I} 8: \mathrm{I}$ and $\mathrm{I} 6: \mathrm{I} / \mathrm{I} 8: \mathrm{I}$ were encountered; these species were not detected in lecithins $B$ or $C$. The reverse is true for $18: 1 / 18: 2$. The great similarity in the force-area characteristics of the different lecithins from rat liver, particularly lecithins $\mathrm{A}$ and $\mathrm{B}$, may be traced back to the replacement of unsaturated fatty acids of different families and alterations in the proportions of the individual lecithin species under different dietary conditions. Apparently, there are several mechanisms operating which attempt to maintain the physico-chemical properties of the lecithin within certain limits. Although the force-area curve for the lecithin sample from essential fatty acid-deficient rats is nearly identical to that obtained from normal animals, it has to be realized that such measurements at the air-water interface are not necessarily applicable to natural membranes. On the other hand, the work of VAN DORP et al. ${ }^{2 \theta}$ and Bergström, DANielsson and SAMUelsson ${ }^{30}$ on the biosynthesis of prostaglandins demonstrated that apart from a possible structural function. in membranes the essential fatty acids also have other functions. A particular function of arachidonate in membrane phospholipids cannot be expected to be deducible from a simple lipid monolayer at the air-water interface. The present experiments demonstrate only that the liquid-crystalline state of the total lecithin from rat liver is preserved in essential fatty acid deficiency and that this result can be accounted for by the composition of the lecithin in terms of its molecular species.

\section{ACKNOWLEDGEMENTS}

The present investigations have been carried out under the auspices of the Netherlands Foundation for Chemical Research (S.O.N.) and with financial aid from the Netherlands Organization for the Advancement of Pure Research (Z.W.O.).

The authors wish to thank Dr. J. Thomasson (Unilever Research Laboratory, Vlaardingen) for supplying the essential fatty acid-deficient rats. The collaboration of Drs. R. F. A. ZwAAL and Mr. H. J. M. Messerschmidt in a number of the experiments is greatly appreciated.

The authors are very indebted to Dr. E. E. Gordon for kindly reading the manuscript.

\section{REFERENCES}

I L. L. M. VAN DeEnEN, Ann. Acad. Sci., 137 (1966) 7I7.

2 L. L. M. van DeEnen, L. M. G. VAN Golde AND R. A. Demel, Biochem. J., 98 (1966) 17P.

3 B. DE VRIES, Chem. Ind. London, (1962) I049.

4 C. B. Barret, M. S. J. Dallas aNd F. B. Badley, Chem. Ind. London, (1962) $105^{\circ}$.

5 L. J. MORRIS, Chem. Ind. London, (1962) 1238.

6 L. J. Morris and A. T. James, in L. J. Morris, New Biochemical Separations, D. van Nostrand, London, 1964, p. 295.

7 H. P. Kaufmann, H. Wessels and C. Bondopadhyaya, Fette, Seifen, Anstrichmittel, 65 (1963) 543 .

8 F. Haverkate and L. L. M. van Deenen, Biochim. Biophys. Acta, 106 (1965) $7^{8 .}$

9 O. Renkonen, J.Am. Oil. Chemists' Soc., 42 (ro65) 208 .

io L. M. G. van Golde, R. F. A. Zwal and L. L. M. van Deenen, Proc. Koninki. Ned. Akad. Wetenschap. Ser. B, 68 (rg65) 255 .

II G. A. E. ARvidson, J. Lipid Res., $6(1965) 574$.

I. O. RENKONEN, Biochim. Biophys. Acta, 125 (1966) 275 .

I 3 E. G. Bligh and W. J. Dyer, Can. J. Biochem. Physiol., 37 (I959) 9 II.

I D. J. Hanahan, J. C. Ditmmer and E. Warashina, J. Biol. Chem., 228 (1957) 685. 
I5 M. M. Rapport and B. Lerner, Biochim. Biophys. Acta, 33 (I959) 3 I9.

I6 F. D. Collins, Biochem. J., 88 (1963) 3 I9.

17 K. Tischer and J. L. GLEN, Biochim. Biophys. Acta, 98 (1965) 502.

i8 L. A. Biran, W. Bartley, C. W. Carter and A. Renshaw, Biochem. J., 93 (1965) 492.

I9 R. M. Johnson and T. ITo, J. Lipid Res., 6 (1956) 75.

20 D. B. Menzel and H. S. Olcott, Biochim. Biophys. Acta, 84 ( $\mathrm{g}_{964}$ ) 133.

2 I R. R. Brenner and A. M. Nervi, $J$. Lipid Res., 6 (1956) 363.

22 P. Savary and P. Desnuelle, Bicchim. Bicphys. Acta, 2 I (1956) 349.

23 F. H. Mattson and L. W. Beck, J. Biol. Chem., 2 I9 (1956) 735.

24 F. D. Collins, Riochem. J., 99 (r966) i 7 .

25 R. A. DEMEL, Thesis, Utrecht, 1966.

26 J. F. MEAD, Federation Proc., 20 (1961) 952.

27 E. Klenk, $J$. Am. Oil. Chemists' Soc, 42 (1965) 580.

28 W. M. F. LEAT, Biochem. J., 9 I (1964) 444.

29 D. A. van Dorp, R. H. Beerthuis, D. H. Nugteren and H. Vonkeman, Biochim. Biophys. Acta, $90\left(\mathrm{I}^{2} 64\right) 204$.

zo S. Bergström, H. Danielsson and B. Samuelsson, Biochim. Biophys. Acta, 90 (1964) 207.

Biochim. Biophys. Acta, 125 (1966) 496-509 